\title{
Sal (Shorea Robusta) Leaves Lignin Epoxidation and Its Use in Epoxy Based Coatings
}

\author{
Ankita Singh, Kapil Yadav, Akhil Kumar Sen* \\ Chemical and Polymer Engineering Department, Birla Institute of Technology, Mesra, 835215, Ranchi
}

\begin{abstract}
Lignin was extracted from Sal leaves by treating with alkaline solution followed by acidification at room temperature. The extracted lignin was first purified by hot water extraction followed by soxhlet extraction with cyclohexane and ethanol mixture. This purified lignin was epoxidized with epichlorohydrin in alkaline medium. FTIR, UV-Visible, TGA and DTA techniques were used to characterize the lignin and its epoxidized form. FTIR spectra are comparable with other lignin structure in the literature. UV-Visible spectra show a long absorption band in the visible region other than the usual absorption in the UV region. The epoxidized form was mixed with epoxy based primer coating and coated on metal panel for corrosion studies by electrochemical analyzer. The Tafel plot shows that the corrosion rate increases with increase in lignin content in the paint composition.
\end{abstract}

Keywords Sal Leaf, Lignin, Epoxidation, Coating

\section{Introduction}

Lignin is a natural polymer found in the plant kingdom. It is one of the abundant materials following cellulose. Between 40 and 50 million tons per annum is produced worldwide as a primarily non commercialized waste product in pulp and paper industries. Its complex three dimensional structure serves as a continuous matrix component in plant cell walls providing mechanical strength and structural support. Lignocellulose structures and compositions vary greatly, depending on plant species, plant parts, growth conditions, etc ${ }^{1}$.

Lignin is a three dimensional phenyl propanol polymer of three phenyl propanaol i.e. p-coumaryl alcohol (p-hydroxy phenyl propanol), coniferyl alcohol (guaiacyl propanol) and sinapyl alcohol (syringyl alcohol) $)^{2,3}$. They are linked mainly by two linkages (e.g. 5-5 and $\beta-1$ linkages) and ether linkages (e.g. $\beta-\mathrm{O}-4$ and $\alpha-\mathrm{O}-4$ ) while the ether linkages are dominant linkages between the three main building blocks. Besides the 20 different types of bonds present in lignin itself, lignin seems to be particularly associated with the hemicellulosic polysaccharides ${ }^{4,5}$. Several applications for the different types of lignin obtained from fractionation and pulping processes have been considered. However, a large problem with the utilization of industrial lignin in certain application areas, such as synthetic polymers, is the heterogeneity of the lignin and the lack of effective methods for

* Corresponding author:

akhilsen@yahoo.co.in (Akhil Kumar Sen)

Published online at http://journal.sapub.org/ajps

Copyright (C) 2012 Scientific \& Academic Publishing. All Rights Reserved isolation of lignin with high purity. It is apparent that a better knowledge is required for the fractional separation and structural characterization of lignin, if it is to be used optimally ${ }^{6}$. The use of lignin for the synthesis of new polymeric materials is the most promising alternative for its revalorization. There has been extensive research for the replacement of phenol in phenol formaldehyde resin due to its similar structure ${ }^{7-9}$. One of the major challenges is the replacement of less reactive lignin due to highly substituted structure in phenol formaldehyde resin system ${ }^{10}$. This can be partially overcome by phenolation or methylolation of lignin before introduction to phenol formaldehyde resin synthesis ${ }^{11-13}$. Literature shows that lignin mixed with epoxy (DGEBA) resin is used for making printed electric boards and it has been found that resins with up to $60 \%$ of lignin content have shown good physical and electrical properties $^{14}$.

Epoxy resins are versatile material but they are costly and the cost reduction of the end product without affecting the properties is the key challenge facing scientists and technologists. One possible solution may be the development of resin by utilization of low cost raw material/ waste product for the development of epoxy resin. This paper deals with the utilization of agricultural waste, such as Sal leaves, for the development of lignin based epoxy resins. Oliviera et al 2006 have extracted lignin from banana leaf and characterized.

$\mathrm{Sal}$ forests is one of the major forests type in South Asia. Its geographic range extends from the southern slopes and lower foothills of the Himalayas to plains, river slopes and valleys in Nepal, Bangladesh, India, Bhutan and South China. In India, Sal forests are spread in about 10.37 million hectors $^{15}$. Sal leaves usually start falling in late winter and peaks 
between February and mid May. In the present study, lignin is extracted from Sal leaves and it is purified by hot water extraction followed by soxhlet extraction in cyclohexane and ethanol solvent. The purified lignin is converted to epoxidized form with epichlorohydrin in alkaline solution. Different structural characterization techniques are used like FTIR, UV-Visible, TGA and DTA. The epoxidized lignin is mixed in various proportions with commercial epoxy based primer coating and coated on metal panel for corrosion studies by electrochemical analyzer.

\section{Experimental}

\section{Material}

Sal leaves collected from local trees for lignin extraction. Industrial grade sodium hydroxide and hydrochloric acid were used for lignin extraction. Epichlorohydrin was obtained from M/s CDH Chemicals, Bombay. Epoxy based primer coating material was kindly donated by M/s Shalimer Paints R\&D Nasik, Bombay.

\section{Extraction of lignin from Sal leaf}

Sal leaves were dried under sunlight and grinded to small pieces in a high speed grinder. These small pieces were dipped in $5 \% \mathrm{NaOH}$ solution and left at room temperature for two days (48 hours). The leaves were filtered out and the filtrate, spent black liquor, was treated with dilute $\mathrm{HCl}$ to make it acidic. Dark brown colored lignin precipitate was settled at the bottom of vessel which was filtered and dried in air oven at $80^{\circ} \mathrm{C}$ until constant weight.

\section{Purification of crude lignin}

The crude lignin powder obtained from the above procedure was dissolved in water and heated to $70^{\circ} \mathrm{C}$ in constant temperature water bath and filtered in hot condition to remove all the water soluble Salts. The solid was extracted in a soxhlet extractor with cyclohexane and ethanol mixture, 1:1 (V/V), for about six to eight hours to complete at least 10 cycles of extraction process. It was first dried under fan and finally dried in air oven to get a pure lignin powder.

\section{Epoxidation of lignin}

The purified lignin powder was taken in a reactor vessel fitted with a mechanical stirrer and a condenser attached with it. Then $20 \%$ of aqueous sodium hydroxide solution was added and stirred for dissolution. The solution was heated to $80^{\circ} \mathrm{C}$ and the epichlorohydrin was added slowly in the ratio of $2: 3(\mathrm{w} / \mathrm{v})$ under stirring condition. The epoxidation process was carried out under continuous heating and stirring up to three hours.

\section{Fourier Transform Infra Red (FTIR) spectroscopy}

The FTIR spectra of the unepoxidized and epoxidized lignin sample were observed in a Shimazdu make IR prestige21 model. DRS technique was used to take the spectra from 4000 to $500 \mathrm{~cm}^{-1}$.

\section{UV- Visible Spectroscopy}

UV-Visible studies were carried out in alkaline lignin solution on UV-Visible spectrophotometer manufactured by Perkin Elmer, USA (model Lambda 25). The test was carried out from $200-800 \mathrm{~nm}$ of wavelength.

\section{Thermal analysis}

The thermal stability of the lignin was studied using a Thermogravimetric Analyzer (Shimazdu Corporation, Japan, model: DTG 60). Thermograms were recorded from room temperature to $800^{\circ} \mathrm{C}$ at a heating rate of $10^{\circ} \mathrm{C}$ per minute and with nitrogen gas flow rate of $30 \mathrm{~mL} / \mathrm{min}$.

Development of Epoxidized lignin based coating preparation

The epoxidized lignin was mixed with an epoxy based primer (supplied by Shalimar paints R\&D Nasik, Bombay) in a ratio of $5 \%, 10 \%$ and $20 \%$ by weight in high speed mechanical stirrer. The final coating solution was prepared and mixed with the hardener in the ratio of 5.11:1 (by weight recommended by the manufacturer) and coated on a steel panel. Pot life was determined for the coating formulation and the corrosion studies were carried out using an electrochemical analyzer.

\section{Electrochemical test}

Corrosion studies of the coated steel panel were carried out on an electrochemical analyzer manufactured by $\mathrm{CHI}$ Instruments USA (model 660B). All electrochemical measurements were carried out at room temperature in $3.5 \% \mathrm{NaCl}$ solution. Test system were consisted of three electrode cell, in which a saturated calomel electrode (SCE), a platinum electrode and a coated panel were used as reference, counter and working electrode respectively. The exposed area of the coated panels to the $\mathrm{NaCl}$ solution was $12 \mathrm{~cm}^{2}$ in all the cases.

\section{Results and Discussion}

Sal leaves become yellow before falling from trees. The falling leaves turn from light brown to brown over the days. Lignin is isolated after acid treatment of alkaline extraction of Sal leaves. This lignin is first purified by hot water extraction followed by soxhlet extraction with cyclohexane and ethanol solvent.

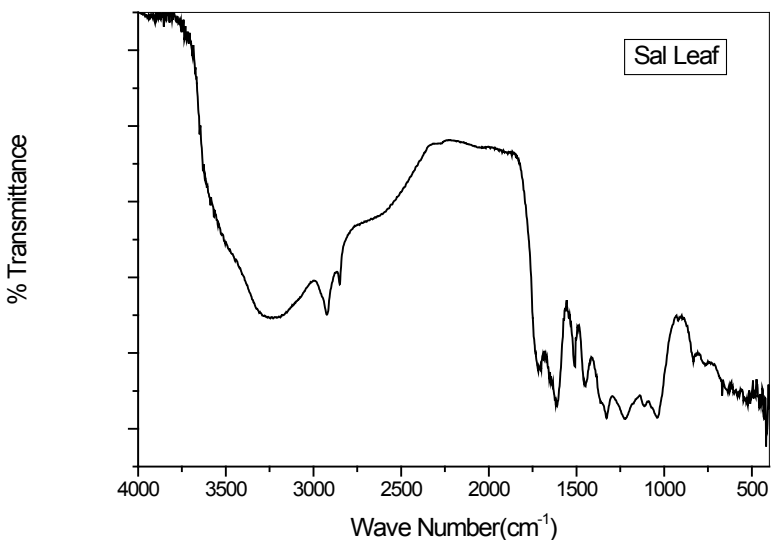

Figure 1. FTIR spectra of Sal leaf lignin

\section{FTIR spectra}

Fig 1 is the FTIR spectra of Sal leaf lignin. The broad peak near $3300 \mathrm{~cm}^{-1}$ is due to the presence of hydroxyl stretching frequency. The strong peak at $2950 \mathrm{~cm}^{-1}$ and $2900 \mathrm{~cm}^{-1}$ are 
due to the $\mathrm{C}-\mathrm{H}$ stretching frequency. The peak near $1680 \mathrm{~cm}^{-1}$ is due to conjugated $\mathrm{C}=\mathrm{O}$ frequency. $\mathrm{C}-\mathrm{H}$ deformation of methyl and methylene are observed near $1460 \mathrm{~cm}^{-1}$. C-H in plane deformation with aromatic ring is observed near 1421 $\mathrm{cm}^{-1}$. The peak $1330 \mathrm{~cm}^{-1}$ is may be due to the syringyl ring structure and $1250 \mathrm{~cm}-1$ is due to the $\mathrm{C}-\mathrm{O}$ guaiacyl ring structure. Aromatic C-H in plane deformation is observed near $1050 \mathrm{~cm}^{-1}$. All the above peaks are comparable with the hard wood and soft wood lignin structure reported in the literature ${ }^{16}$.

Fig 2 is the FTIR spectra of epoxidized Sal leaf lignin. The epoxidation changes slightly the peak positions and new peaks are observed at finger print region. Two new peaks near $775 \mathrm{~cm}^{-1}$ and $675 \mathrm{~cm}^{-1}$ may be due to the epoxy ring present in the molecular structure which is absent in the unepoxidized form.

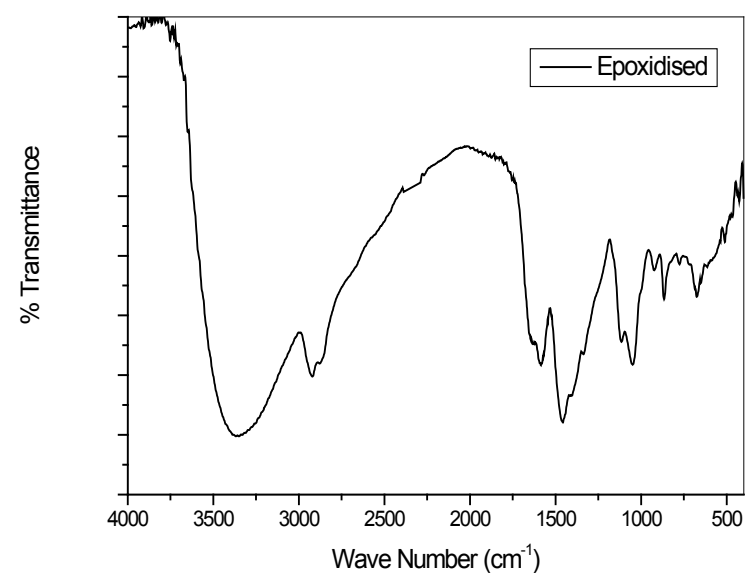

Figure 2. FTIR spectra of epoxidized Sal leaf Lignin sample

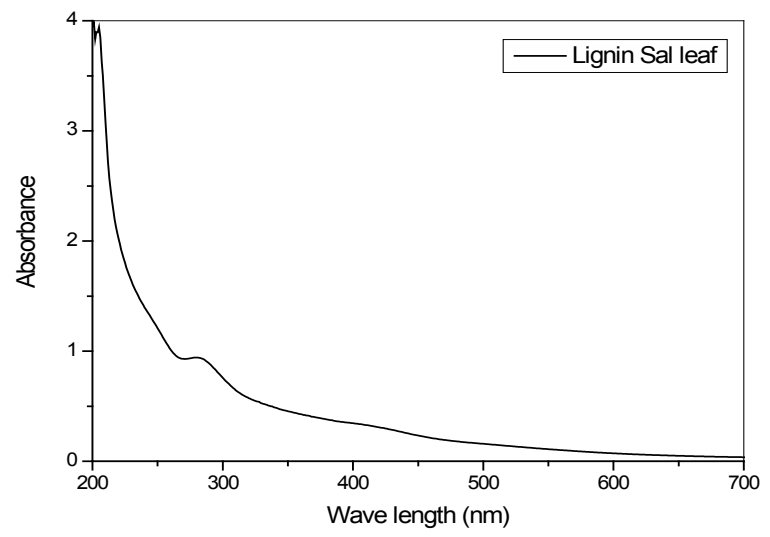

Figure 3. UV-Visible spectra of lignin extracted from Sal leafs

\section{UV-Visible spectrophotometer}

Figure 3 is the UV-Visible spectra of Sal leaf lignin in alkaline solution. The absorption spectrum is shown from $200 \mathrm{~nm}$ to $700 \mathrm{~nm}$. The high absorption in the range of $200-220 \mathrm{~nm}$ is due to $\pi \rightarrow \pi^{*}$ transition of the aromatic ring. Absorption platue near $270-285 \mathrm{~nm}$ is due to the phenolic structure of the free and etherified hydroxyl group. The shifting of phenolic peak (bathochromic shift) is due to the extended conjugation with the ring structure.

The absorption band above $300 \mathrm{~nm}$ indicates the presence of conjugated structure present with the aromatic moieties.
The important point is the absorption band above $350 \mathrm{~nm}$ and is extended up to $600 \mathrm{~nm}$. Literature reported the lignin absorption band up to $350 \mathrm{~nm}^{14,17-18}$. The absorption band in the visible region $(400 \mathrm{~nm}$ to $600 \mathrm{~nm})$ is responsible for the dark brown colour of the extracted lignin. Lignin is a naturally occurring large molecule and its structure depends on the source and climatic conditions. So it is difficult to predict the exact structure of the lignin at present.

\section{Thermal studies}

Figure 4 is the TGA curve of Sal leaf lignin from room temperature to $800^{\circ} \mathrm{C}$. The continuous weight loss takes place from room temperature to $800^{\circ} \mathrm{C}$. The first stage weight loss from room temperature to $110^{\circ} \mathrm{C}$ may be due to the moisture in the sample. Figure 5 is the DTA curve of the Sal leaf lignin. Here the two endothermic peak is observed. One from room temperature to $110^{\circ} \mathrm{C}$ which may be due to the removal of water. The second endothermic peak observed after $400^{\circ} \mathrm{C}$ with a peak value $440^{\circ} \mathrm{C}$. One exothermic peak is observed near $500^{\circ} \mathrm{C}$. The overall curve is exothermic in nature which indicates that continuous degradation is taking place. Literature shows that the degradation of lignin depends on the source and method of extraction $^{19-20}$.

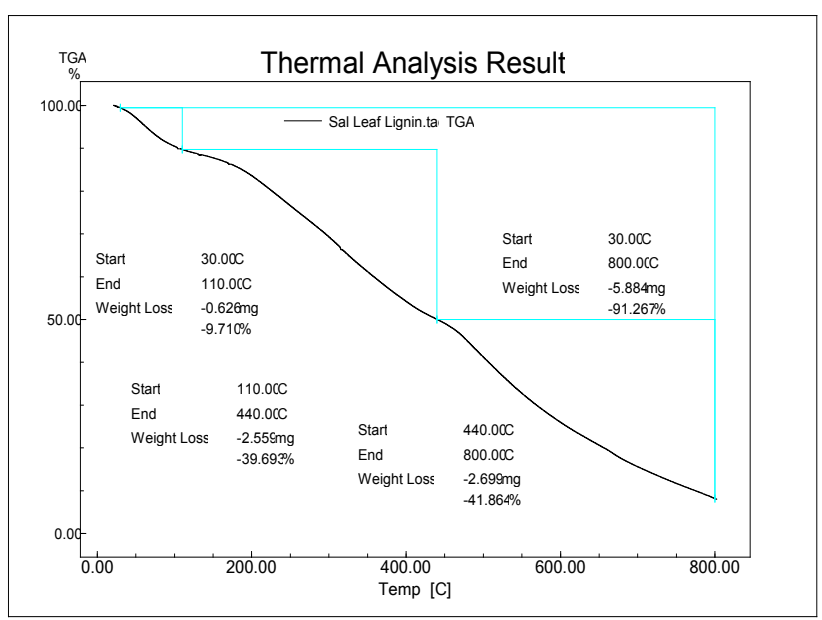

Figure 4. TGA curve of Sal leaf lignin

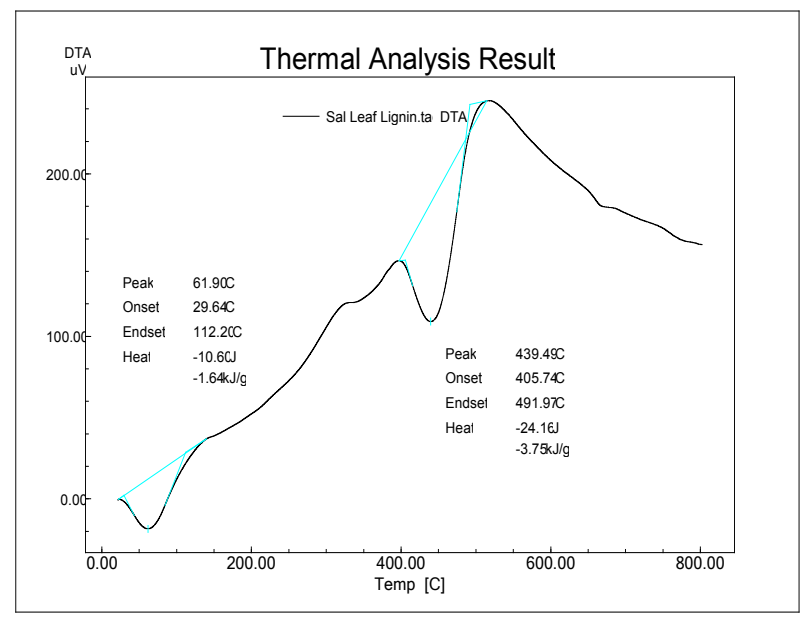

Figure 5. DTA curve of Sal leaf lignin 


\section{Pot life of the paint}

Pot life of paint is related to viscosity of the paint system. It is verified after mixing epoxy paint with a hardener. For practical purposes, a reasonable pot life is required. Here we have checked the deviation from the optimized commercial product (blank sample). Figure 6 shows the pot life variation with varying lignin percentage. The pot life increases with $5 \%$ epoxidized lignin but after that the pot life decreases. Pot life is lowered for $20 \%$ epoxidized lignin containing paint but the decrease is not much.

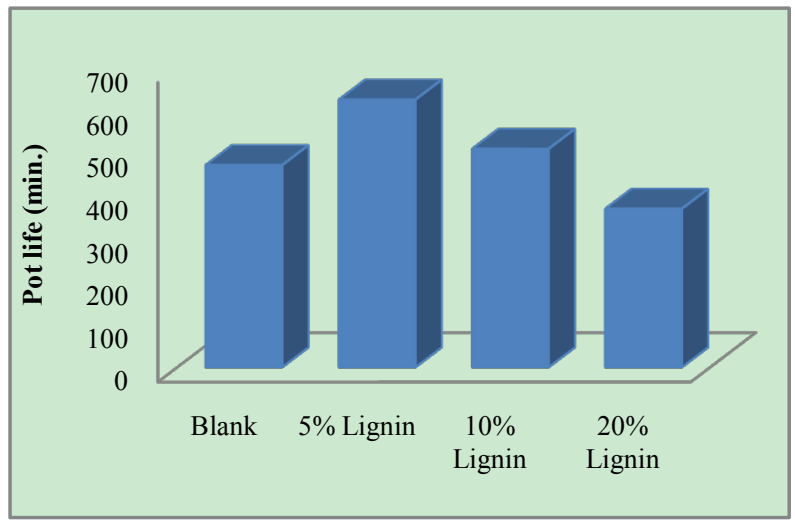

Figure 6. Pot life of coating formulation

Table 1. Corrosion rate of different epoxidized lignin containing primer

\begin{tabular}{|c|c|c|c|}
\hline $\begin{array}{c}\text { Sample No- } \\
\text { menclature }\end{array}$ & $\begin{array}{c}\text { Epoxidized } \\
\text { lignin (wt\%) }\end{array}$ & \multicolumn{2}{|c|}{ Corrosion Rate (mil/year) } \\
\hline & & 0 Hour & 24 Hour \\
\hline E0 & - & $1.843 \mathrm{e}^{-001}$ & $2.620 \mathrm{e}^{-001}$ \\
\hline E5 & 5 & $2.176 \mathrm{e}^{000}$ & $4.690 \mathrm{e}^{000}$ \\
\hline E10 & 10 & $1.836 \mathrm{e}^{000}$ & $1.155 \mathrm{e}^{+001}$ \\
\hline E20 & 20 & $1.588 \mathrm{e}^{+001}$ & $1.822 \mathrm{e}^{+001}$ \\
\hline
\end{tabular}

\section{Electrochemical test}

Table 1 shows the variation of corrosion rate for different proportions of epoxidized lignin content in epoxy primer for zero hour and 24 hours. This shows that the rate of corrosion increases with increase in lignin content in the sample. In all the cases the corrosion rate is high this may be due to the higher solubility of the lignin compound. This indicates the extracted lignin structure is highly substituted due to which less covalent bond formation with the epoxy matrix takes place.

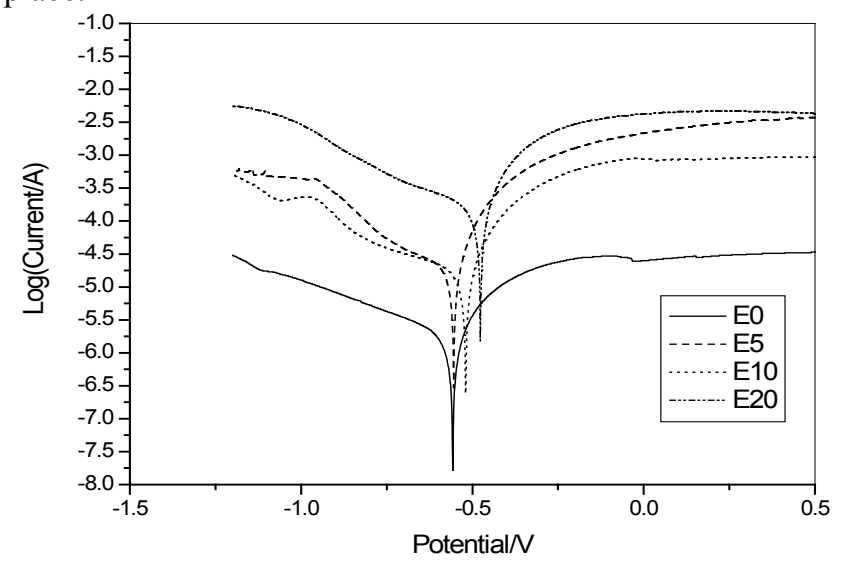

Figure 7. Instant Tafel plot of epoxidized lignin containing primer coating
Figure 7 is the instantaneous Tafel plot of epoxidized lignin containing primer in Salt solution. Here both cathodic and anodic current is higher than the blank sample. This indicates the corrosion rate will be higher in the lignin containing sample. The rates are given in table 1 . Figure 8 is the Tafel plot of epoxidized lignin containing primer after 24 hour dipping in Salt solution. Here similar effects are observed i.e. both cathodic and anodic current increases with increase in lignin concentrations. But the current is low for sample containing $5 \mathrm{wt} \%$ lignin.

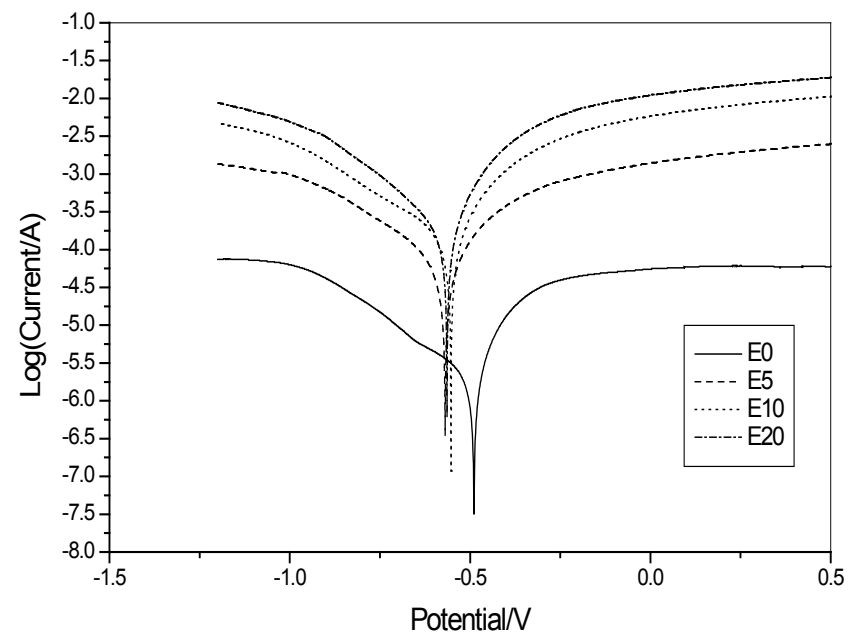

Figure 8. Tafel plot of epoxidized lignin containing primer coating after 24 hour

\section{Conclusions}

Sal leaf lignin was extracted by treating with alkali followed by acidification. The extracted lignin was purified and epoxidized by epichlorohyrin in alkaline medium. FTIR, UV-Visible, TGA and DTA techniques were used to characterize the lignin and its epoxidized form. FTIR spectra indicate the presence of equivalent structure of lignin in the extracted material. UV-Visible spectra are comparable with the other lignin compounds reported in the literature. But more absorption band above $350 \mathrm{~nm}$ which extends in the visible region. This indicates more conjugated structure present in the extracted sample. The thermal stability is lower than the lignin compounds reported in the literature and continuous weight loss takes place up to $800^{\circ} \mathrm{C}$. This may be due to the highly conjugated structure of lignin with the aromatic ring. The corrosion studies of epoxidized lignin containing primer shows higher rate of corrosion than standard epoxy containing primer. However $5 \mathrm{wt} \%$ lignin content sample shows somewhat lower rate of corrosion. This is due to the highly substituted lignin structure which can be modified further with phenol formal based resin system.

\section{ACKNOWLEDGEMENTS}

The authors are grateful to acknowledge the Central Instrumentation Facility (CIF) at Birla Institute of Technology, 
Mesra established on 2006 in Technical Education Quality Improvement Programme (TEQIP) funded by World Bank for the state of the art Instrumentation facility. The authors are also grateful to $\mathrm{M} / \mathrm{s}$ Shalimar Paints for providing epoxy based primer coating material.

\section{REFERENCES}

[1] Y.H.P. Zhang, S.Y. Ding, J.R. Mienlenz, J.B. Cui, R.T. Elander, M. Laser,M.E. Himmel, J.R. Mc Millan and L.R. Lynd, Biotechnol. Bioeng. 97 (2) (2007) 214.

[2] H.E.Desch and J.M.Dinwoodie, Timber: structure, properties, conversion and use. (Food Products Press, 7th ed. 1996).

[3] G.Tsoumis, Science and technology of wood: structure, properties, utilization. (Van Nostrand Reinhold, NY 1991).

[4] C.W. Ford, Carbohydr. Res. 147 (1986) 101.

[5] O. Theander, in: New Approaches to Research on Cereal Carbohydrates, Edited R.D. Hill, Elsevier, Amsterdam, p 217 (1985).

[6] J. RuncCang Sun and Tomkinson, Sep. Purif. Technol. 24 (2001) 529.

[7] M.V. Alonso, M. Oliet, J.M. Perez and F. Rodriguez, Thermochim Acta 419 (2004) 161.

[8] M.A.Khan, S.M.Ashraf and V.P.Malhotra, J. Appl. Polym. Sci. 92 (2004) 3514.
[9] M.Turunen, L. Alvila, T.T. Pakkanen and J. Rainio, J. Appl. Polym. Sci.88 (2003) 582.

[10] A.Effendi, H.Gerhauser, A.V.Bridgwater, Renewable Sustainable Energy Rev 12 (2008) 2092.

[11] M.V.Alonso, M. Oliet, F. Rodrıguez, J.Garcıa, M.A.Gilarran $\mathrm{z}$ and J.J.Rodriguez, Bioresour Technol, 96 (2005) 1013.

[12] N.E.El Mansouri, A.Pizzi and J.Salvado, J. Appl. Polym. Sci. 103 (2006) 1690.

[13] L.L.Kosbar, J.D.Gelorme, R.M. Japp and W.T.Fotorny, J. Ind. Ecol. 4 (2001) 93.

[14] L. Oliveira, D. V. Evtuguin, N. Cordeiro, A. J. D. Silvestre, A. M. S. Silva, I. C. Torres, J. Agric. Food Chem. 54 (2006) 2598.

[15] I. P. Sapkota, Ph.D. Thesis, Swedish University of Agricultural Sciences, Alnarp (2009).

[16] S. Kubo and J. F. Kadla, Biomacromolecules , 6 (2005) 2815.

[17] A. M. L. Seca, J. A. S. Cavaleiro, F. M. J. Domingues, A. J. D. Silvestre, D. Evtuguin, and C. P. Neto, J. Agric. Food Chem. 48 (2000) 817.

[18] T.Higuchi, Y.Ito and I. Kawamura, Phytochemistry, 6 (1967) 875.

[19] G Jiang, D.J.nowakowski, A. V. Bridgwater, Therchimica Acta, 498 (2010) 61.

[20] O.Faix, D. Meier, O. Beinhoff, Biomass, 18 (1989) 109. 